\title{
Agência, teleologia e força controladora: uma abordagem sociocognitiva do sobrenatural em Milagre Chué, de João Antonio
}

\author{
Agency, Telicity and Controlling Force: a Social-Cognitive Approach \\ to the Supernatural in Milagre chué ("A Teeny-Weenie Miracle”), by João Antonio
}

\author{
FÁbio Lucas Pierini [fabiopierini@gmail.com] \\ Universidade Estadual de Maringá (Maringá, Paraná), Brasil
}

Ana Cláudia Paschoal [anaclaudiapaschoal@hotmail.com]

Colégio Paroquial Nossa Senhora do Carmo (Paranavaí, Paraná), Brasil

\begin{abstract}
RESUMO
A abordagem sociocognitiva da narrativa fantástica (ou portadora de elemento sobrenatural em geral) tem por objetivo compreender as razões que permitam a construção do sentido numa narrativa de ficção que, embora realista, apresenta eventos inverificáveis e ou irreproduzíveis na realidade referencial, orientada pelas Ciências Naturais. Estudos preliminares (Pierini 2017) permitem afirmar que, por exemplo, o fantástico é um gênero narrativo que se consolida no século XIX em reação ao desaparecimento acelerado da sociedade europeia até então baseada em relações forjadas no decorrer do Neolítico. Essa reação se deu por meio de narrativas de ficção que apresentam eventos sobrenaturais num mundo em que eles não deveriam ocorrer a partir de um estilo narrativo que se apropria tanto da reportagem investigativa quanto dos relatórios científicos, colocando sub-repticiamente ao leitor que o mundo sobrenatural ainda existe, mas de forma dissimulada. No conto Milagre chué, de João Antonio, encontramos como evidências dessa estrutura os conceitos cognitivos de agência, teleologia e força controladora, mesmo se tratando de uma narrativa que permita mormente a uma leitura alegórica.
\end{abstract}

\section{Palavras-Chave}

Abordagem sociocognitiva da narrativa; João Antônio; Milagre chué; sobrenatural

\section{Abstract}

The social-cognitive approach of the fantastic narrative (or presenting supernatural elements in general) aims to understand the reasons that allow the construction of meaning in a narrative fiction that, although realistic, presents unverifiable and irreproducible events in the referential reality, guided by the Natural Sciences. Preliminary studies (Pierini 2017) allow us to affirm that the fantastic, for example, is a narrative genre that consolidates in the nineteenth century in reaction to the accelerated disappearance of European society hitherto based on forged relations during the Neolithic period. This reaction has occurred through fiction narratives that present supernatural events in a world where they should not occur from a narrative style that appropriates both investigative reporting and scientific reports, surreptitiously telling to the reader 
that the supernatural world still exists, but in a disguised way. In Miracle Chué ("A teennie-winnie miracle"), by João Antonio, we find as evidence of this structure the cognitive concepts of agency, teleology and controlling force, even this narrative permits mostly an allegoric reading.

\section{KEYWORDS}

Social-cognitive literary approach; João Antonio; Milagre chué; supernatural

RECEBIDO 2019-04-20; ACEITE 2019-09-17

\section{Uma abordagem sociocognitiva}

A abordagem sociocognitiva da narrativa fantástica é aquela que considera todo texto ficcional uma resposta sociocognitiva a uma contingência sociocultural, ou seja, o autor buscaria, por meio de sua história, converter os fragmentos dispersos da realidade captados pelos seus sentidos num todo coerente e dotado de significado que amenize a angústia da imprevisibilidade dos eventos vivenciados (Pierini 2017). Portanto, é preciso considerar que o que hoje entendemos como ficção só foi distinguido como tal a partir da Renascença, quando uma nova noção do real passou a dominar a arte (Faivre 1991), ou seja, quando ficou estabelecida, ao menos para a sociedade Ocidental, a diferença entre real e não real a partir de critérios sustentados pelas Ciências Naturais. Até então, tudo o que era escrito como narrativa, mesmo que deliberadamente inventado por um autor identificável, era considerado passível de ocorrer, independentemente da presença de eventos sobrenaturais.

Sucessivamente, Humanismo, Renascença, Iluminismo e revoluções industriais mudaram, seja a partir de princípios filosóficos, seja a partir de invenções e de progressos tecnológicos, a visão de mundo de parte considerável das pessoas. Dessa forma, muito do que se considerava real num passado não muito distante, passou a ser mera superstição ou crendice e gêneros narrativos como o maravilhoso e o feérico foram relegados a uma categoria inferior, pois a narrativa séria, destinada a um público ilustrado e respeitável, devia obedecer aos critérios de realismo baseados nos parâmetros das Ciências Naturais.

No entanto, essa postura apresenta certas limitações em tempos econômica e socialmente difíceis. Em sua Arte de escrever ao gosto do público, o Marquês de Sade (2000: 45) afirma que, durante o período revolucionário europeu por ele vivenciado (século XVIII), para os leitores, as condições de vida e as perspectivas de futuro eram tão sofridas que não havia interesse em evasão total da realidade, porque o leitor sabia que aquilo seria falso, tampouco na simulação da realidade imediata, porque as pessoas estavam fartas dela. O ideal seria encontrar um meio termo entre ambos, mas que tal caminho se mostrava cheio de inconvenientes.

Quais seriam então os inconvenientes levantados por Sade para contar uma história que atendesse tanto aos critérios de realismo quanto ao gosto pela evasão sem cair no maravilhoso puro nem no prosaísmo entediante? A nosso ver, é preciso inicialmente entender qual a noção de real do público. É preciso compreender que, exceto para ateus convictos, há algo de sobrenatural no mundo real. E isso não é fruto de uma educação religiosa nem de uma cultura supersticiosa, mas 
das próprias forças da Evolução: como a realidade é captada como fragmentos esparsos pelos nossos sentidos, nós dependemos da linguagem - e mais especificamente das narrativas - para tornar o real algo coerente e assimilável dentro de uma escala humana de compreensão, que Atran (2003: 64-67) chama de "estrutura teleológica de eventos". Porém, não basta apenas criar uma história com personagens, narrador, tempo, espaço, foco narrativo, enredo, etc. para dar significado ao real. Estes e outros elementos narrativos precisam encontrar respaldo na mente humana para fazerem sentido, coincidir com a expectativa intuitiva (Boyer 2003: 90-97) das relações de causa e efeito na natureza ou a pretensa narrativa ficará ininteligível.

Assim sendo, admitimos que a narrativa fantástica é aquela que realisticamente apresenta um evento irreproduzível e ou inverificável na realidade referencial. Isso significa que, ao introduzir um elemento sobrenatural numa narrativa de ficção, o autor considera as implicações desse elemento na realidade referencial, ou seja, aquela que pode ser compartilhada por autor e leitor fora de seu espaço mental individual e cujas relações de causa e efeito são orientadas pelas Ciências Naturais. Essa orientação descarta toda e qualquer interferência de seres, objetos ou forças sobrenaturais nos seres, objetos e forças da realidade referencial.

A pergunta que se faz então é: isso não é contraditório? E se o sobrenatural for apenas algo que a Ciência ainda não descobriu? E se esses seres realmente existirem mas forem indetectáveis pelos recursos tecnológicos atualmente disponíveis? Esses argumentos são válidos apenas se considerarmos a narrativa fantástica um experimento estético da parte do autor para apreciação meramente intelectual do leitor. A Ciência trabalha com verdades provisórias, o que quer dizer que, no momento em que nos encontramos, não há provas da existência de seres sobrenaturais em nossa realidade referencial e devemos considerar que a narrativa fantástica surge sociocognitivamente da necessidade de combater essa afirmação científica. Caso algum dia se prove a existência de seres, objetos ou forças sobrenaturais, não apenas a Ciência mudará suas afirmações sobre o caso como também o gênero narrativo fantástico perderá sua função sociocognitiva, que é a de chamar a atenção do leitor para eventos do mundo real que pressupõem a existência do sobrenatural em oposição às negações da Ciência a respeito.

\section{O real e o sobrenatural: coincidências fortuitas e estados alterados de consciência}

E agora chegamos ao cerne da nossa questão: que eventos do mundo real apresentam-se à nossa mente como evidências da existência de seres, objetos e forças sobrenaturais? Ao considerarmos o célebre artigo de Freud, O inquietante (2010), bem como a afirmação de H.P. Lovecraft sobre o medo do desconhecido como emoção mais forte e mais antiga da raça humana (2008: 13), trata-se dos estados alterados de consciência (sonho, loucura, drogas) e as coincidências fortuitas (quando se imagina uma relação de causa e efeito entre eventos independentes). O conceito de Freud lida basicamente com a impressão de que tanto um ser, objeto ou acontecimento estranho possa apresentar algo de familiar quanto algo já conhecido constitua-se de maneira estranha aos olhos do observador. Trata-se de um conflito entre a percepção e a consciência que impele o observador a questionar sua visão de mundo e sua noção do real - orientadas a partir das Ciências Naturais. 
Entenda-se que a narrativa fantástica, constituída como uma resposta ao paradigma científico, não é uma forma de convencer o leitor de que o sobrenatural existe nem de provar aos cientistas que eles estão errados, mas de plantar a semente da dúvida em ambos: não se trata exclusivamente de criar uma narrativa ambígua ou sobre cujos eventos se deva hesitar na busca de uma solução, mas fazer com que se duvide do discurso científico a respeito da realidade referencial: na primeira metade do século XIX já se viam os efeitos do Iluminismo e das revoluções industriais sobre a sociedade Europeia Ocidental e a perspectiva de não haver transcendência tornou insuportável a vida para um grande contingente que não via nem na economia (baixos salários, longas jornadas de trabalho) nem na religião (especialmente o cristianismo, que abandonou seu lado "mágico") uma saída para suas angústias.

Segundo Jean Fabre (1992), essa falta de perspectiva transcendental é a esquizofrenia prometeica, causada pelo conflito interno do homem moderno, alinhado ao paradigma do tempo horizontal (científico e inquietante) que não pode mais retomar o caminho do tempo vertical (mágico e reconfortante):

Car, en définitive, c'est bien de cela qu'il s'agit, au moment où, autour des années 1800 et à lère romantique, se constitue le genre fantastique. A ce carrefour de l'histoire, la mentalité "moderne" est devenue schizoïde. Ne pouvant plus survaloriser l'expérience par l'existence de la ratio, ne pouvant pas encore faire triompher le logos par résistance du mythos, la conscience occidentale "prométhéenne" est écartelée entre deux exigences contradictoires. Prométhée schizophrène, éclaté et duel, ne saurait pas échapper au bec qui le ravage que par lécriture. Son seul salut: arracher une plume au vautour (Fabre 1991: 47).

Como saída pela escrita, é o que depreendemos ser, a partir das ideias de Terence Hines (2003) e Bruce Hood (2012), [trata-se do] viés de confirmação desencadeado pelos estados alterados de consciência e pelas coincidências fortuitas. Para entender esse processo, recorremos ao trabalho de Scott Atran (2002) sobre as razões cognitivas da religião e foi possível identificar na narrativa fantástica uma estrutura semelhante segundo a qual todo evento sem causa aparente é atribuído a um agente (agência) dotado de um propósito (teleologia) que interfere na cadeia de acontecimentos da realidade referencial por meio de uma força controladora (sobre si próprio ou sobre outrem):

Humans are cognitively susceptible to invoke supernatural agents whenever emotionally eruptive events arise that have superficial characteristics of telic event structures with no apparent CONTROLLING FORCE. These include chaotic or chance events (earthquakes, thunderstorms, floods, drought), uncertain events (disease, war, famine, loneliness), and future events that are normally beyond a person's control but that people cannot avoid trying to manage, such as critical periods in the human life cycle (birth, puberty, old age, death). Awareness of death is one universal cognition that is especially anxiety-provoking (Atran 2003: 66).

Isso significa que naturalmente tendemos a atribuir a autoria de um evento a alguém e quanto mais extraordinário o evento, mais extraordinária será sua explicação e mais ainda o será seu agente desencadeador. Evidentemente tal raciocínio pode ser aplicado a diferentes gêneros nar- 
rativos além do fantástico, como o próprio mito religioso, as lendas, o maravilhoso medieval, os contos de fadas, entre outros. Por essa razão é necessário entender a qualidade do elemento sobrenatural empregado no texto, ou seja, qual sua função na narrativa e quais suas implicações no enredo.

Conforme já explicado, não consideramos o texto como um elemento com fim em si. Ele depende de suas relações com a realidade referencial para ser inteligível e, consequentemente, constituir uma experiência significativa para seu leitor. Antes de tudo, o autor tenta, por meio de seu texto, compartilhar uma visão de mundo e propõe, na medida em que o leitor realiza o percurso narrativo, que ele "vivencie" por meio da leitura acontecimentos que demonstrem a validade de seus argumentos. É preciso considerar também que, embora tenhamos adotado, neste trabalho, como paradigma para o real a realidade referencial orientada pelas Ciências Naturais (segundo as quais o sobrenatural não existe), autor e leitor podem perfeitamente acreditar na existência do sobrenatural e considerá-lo real mesmo hoje em dia. Além disso, mesmo pessoas céticas, agnósticas e ateias reagem intuitivamente a narrativas em que o sobrenatural esteja presente, atribuindo significado aos seus eventos, mesmo que conscientemente não acreditem neles, porque isso é inerente ao ser humano - desconsideramos aqui, portanto, a "suspensão temporária da descrença”, pois isso pressuporia que todo ser humano é cético, o que não é verdade. Para nós, automaticamente acreditamos para depois desacreditar e não o contrário.

Em dois momentos de seu artigo sobre a periodização do fantástico, Faivre explica inicialmente que até o século XVIII era praticamente impossível escrever sobre um sobrenatural no qual não se acreditasse:

D’une manière générale [...] on n'imagine pas encore qu'un art soit fondé sur des principes purement formels, par exemple qu'on puisse mettre dans une œuvre un surnaturel auquel on ne croit pas. Introduire dans un récit de fiction un surnaturel de surprise risquerait dêtre mal compris, du moins jugé comme un acte de superstition. On publie bien de contes où interviennent des éléments du monde suprasensible, mais d’emblée ils se donnent pour tels, donc ressortissent toujours plutôt au merveilleux [...] Selon Breitinger, le merveilleux - "das Wunderbare" entendons par là le surnaturel - est certes conciliable avec la raison, voire aide à atteindre un sommet de l'art, mais à la condition qu'on le tienne à l'intérieur des limites d'un certain vraisemblable (Faivre 1991: 18-19).

Mais adiante, sobre o último quarto do século XVIII, Faivre complementa que

Pourtant, l'on observe qu'alors le jeu avec le numineux, tout en restant jeu - mais au sens, de plus en plus de "littérature" - tend progressivement à remplacer le numineux comme croyance, processus sans lequel n’aurait pas été possible le fantastique en tant que genre spécifique. Quand on cesse de croire en l'existence objective des êtres surréels, subsiste néanmoins le noyau émotionnel dont ils tiraient leur probable origine, et dont il s'agit dès lors de faire nouvel usage, avec efficacité et selon des règles esthétiques (Faivre 1991: 20).

Com esse "núcleo emocional", Faivre, assim como Lovecraft (2008), alertam para o fato de que narrativas com conteúdo sobrenatural só são passíveis de compreensão porque há algo em nós, algo primitivo e que o processo civilizatório não conseguiu remover: 
Embora a zona do desconhecido venha se contraindo regularmente há milhares de anos, um reservatório infinito de mistério ainda engolfa a maior parte do cosmo exterior, enquanto um vasto resíduo de associações poderosas herdadas se agarra a todos os objetos e processos que um dia foram misteriosos, por melhor que hoje possam ser explicados. E, mais que isso, existe uma fixação fisiológica real dos velhos instintos em nosso tecido nervoso que os tornaria misteriosamente operantes mesmo se a mente consciente fosse purgada de todas as fontes de assombro (Loveraft 2008: 15).

Por essa razão, optamos por um caminho teórico que assimile conhecimentos produzidos no campo da antropologia cognitiva e da psicologia evolutiva, para entender a relação de sentido produzida por narrativas possuidoras de elementos sobrenaturais como elaboradas por autores que têm uma mensagem cujo conteúdo precisa ser codificado a partir da personalização de eventos de causa desconhecida.

\section{Agentes sobrenaturais: propósito e força controladora}

Dessa forma, independentemente da visão de mundo de cada um de nós, nossa noção do real é compartilhada, pois depreendemos o real a partir de nossa capacidade de fazer inferências (Boyer 2003: 88), apoiados tanto em categorias ontológicas (pessoa, animal, planta, artefato e substância) quanto em módulos cognitivos (física intuitiva, biologia intuitiva e psicologia intuitiva) (Atran 2002). Dessa matriz que usamos para varrer o mundo em busca de informações que nos permitam sobreviver, resultam sentimentos que precisam ser explicados (normalmente por meio de narrativas) e permitir que o indivíduo se situe numa totalidade cósmica e obtenha um propósito para sua existência. Cada cultura, em função de contingências socioeconômicas e culturais, irá desenvolver um conjunto de narrativas que dê sentido à existência de cada membro de sua coletividade exatamente por participar dela, constituindo sua visão de mundo. Assim sendo, podemos afirmar que a esquizofrenia prometeica de Jean Fabre (1991) nasce, considerando os estudos cognitivos da literatura, do conflito entre noção do real (que nos permite perceber coisas ainda inexplicadas) e a visão de mundo construída pelas narrativas fundadoras da coletividade em que estamos inseridos.

A visão de mundo do europeu ocidental desiludido com as promessas de um mundo melhor, abstraídas do Positivismo (Bozzetto 1980), permitiu o surgimento e consolidação da narrativa fantástica em sua cultura no século XIX: mesmo entre as pessoas menos afeitas a discussões metafísicas, a narrativa fantástica permitia o acesso a uma visão de mundo que colocava as coisas numa perspectiva mais harmonizada com suas inquietações, o que explica sua popularidade até os dias de hoje.

O público brasileiro também aprecia a literatura fantástica, especialmente aquela produzida na Europa, nos Estados Unidos e, guardadas as devidas diferenças de gênero narrativo, no Japão. Perceba-se que o que consideramos narrativa fantástica aqui se baseia tanto nos pressupostos da sociocrítica de Jean Fabre (1992), Roger Bozzetto (1992), Bozzetto e Huftier (2004), Antoine Faivre (1991) e Irène Bessière (1974) quanto na abordagem cognitiva de Jonathan Gottschall (2012). A partir de tais referenciais nos propomos a um estudo de como a mente humana reage a um 
texto ficcional a partir da interação entre o social e o psíquico, ou seja, a narrativa como forma de mediar um lugar no meio social para o indivíduo, atribuindo-lhe um propósito. Isso descarta a possibilidade de o texto ser um objeto com fim em si, destinado apenas para a apreciação intelectual do leitor, pois mesmo os recursos estéticos mais sofisticados são mobilizados pelo autor em função de sua mensagem. Uma narrativa sem mensagem é ininteligível.

Mas como a mente humana cria as histórias que enquadram o real fragmentado e lhe dá sentido? Gottschall, ao citar a pesquisa do neurocientista Michael Gazzaniga chama a atenção para o fato de o cientista ter

identified specialized circuitry in the left hemisphere that is responsible for making sense of the torrent of information that the brain is always receiving from the environment. The job of this set of neural circuits is to detect order and meaning in that flow, and to organize it into a coherent account of a person's experience - into a story, in other words. Gazzaniga named this brain structure "the interpreter". (Gottschall 2012: 1168/3695, Kindle Edition).

Isso quer dizer que contar histórias é uma forma de organizar o real ao nosso redor principalmente porque faz parte de nossa biologia:

The left brain is a classic know-it-all; when it doesn't know the answer to a question, it can't bear to admit it. The left brain is a relentless explainer, and it would rather fabricate a story than leave something unexplained. Even in split-brain subjects, who are working with one-half of their brains tied behind their backs, these fabrications are so cunning that they are hard to detect except under laboratory conditions (Gottschall 2012: 1200/3695, Kindle Edition).

Mais adiante, Gottschall compara nosso cérebro ao trabalho do detetive Sherlock Holmes, o qual, diferentemente do que pensamos, não é um gênio que descobre tudo somente pela observação e pela dedução. Na verdade, Holmes acerta suas conclusões simplesmente porque o autor, Arthur Conan Doyle, quer que os indícios apontados signifiquem exatamente o que Holmes diz, pois, se tentarmos desconstruir o raciocínio do detetive britânico toda vez que ele descobre algo somente pela observação e dedução, perceberemos haver várias outras possibilidades tão verdadeiras quanto as escolhidas:

We each have a little Sherlock Holmes in our brain. His job is to "reason backwards" from what we can observe in the present and show what orderly series of causes led to particular effects. Evolution has given us an "inner Holmes" because the world really is full of stories (intrigues, plots, alliances, relationships of cause and effect), and it pays to detect them. The storytelling mind is a crucial evolutionary adaptation. It allows us to experience our lives as coherent, orderly, and meaningful. It is what makes life more than a blooming, buzzing confusion [...] The storytelling mind is allergic to uncertainty, randomness, and coincidence. It is addicted to meaning. If the storytelling mind cannot find meaningful patterns in the world, it will try to impose them. In short, the storytelling mind is a factory that churns out true stories when it can, but will manufacture lies when it can't (Gottschall 2012: 1236-1245/3695 Kindle Edition). 
Gosttschall justifica esse resultado evolutivo em função da vantagem que a espécie humana adquiriu ao ser capaz de encontrar padrões na realidade e tomar decisões que desencadearam sua sobrevivência. Assim, nossa capacidade de contar e compreender histórias se combina com nossa capacidade de detectar padrões no meio ambiente e criar explicações que nos permitam viver com mais segurança por tornar o futuro menos imprevisível.

\section{Gênero narrativo e cultura: o fantástico é possível fora da Europa do século XIX?}

Entretanto, mesmo que o público brasileiro aprecie a literatura fantástica dentro da proposta do conflito entre visão de mundo e noção do real, por que os grandes autores brasileiros, aqueles estudados nas universidades e nas escolas de ensino fundamental e médio, quando diante da escrita desse gênero (bem como outros próximos) não o realizam da mesma maneira que seus homólogos estrangeiros? Uma explicação à qual podemos chegar após este breve percurso crítico e teórico a respeito da abordagem sociocognitiva da narrativa fantástica é a de que os autores brasileiros, mesmo os do século XIX, como Machado de Assis, Álvares de Azevedo ou Joaquim Manuel Macedo, não vivenciaram as mesmas contingências socioculturais que seus pares europeus. Nem mesmo os autores estadunidenses, mais próximos da "escola" gótica anglo-saxã, produzem uma obra totalmente alinhada àquela elaborada pelos autores do velho continente: segundo Bozzetto (1988), os autores dos Estados Unidos buscaram deliberadamente criar uma literatura completamente nova, de maneira a se afastar das influências culturais da Inglaterra e consequentemente da Europa.

Assim sendo, podemos considerar que a narrativa fantástica propriamente dita é uma reação sociocognitiva às contingências socioculturais advindas das revoluções industriais sobre uma população que viveu durante séculos dentro de uma visão de mundo consolidada no Neolítico (Bozzetto e Huftier 2004: 83). Mais do que isso, é essa relação de necessidade de expressão que faz do fantástico um gênero em si. Populações fora dessa tradição cultural podem até compreender e apreciar narrativas produzidas nesse esteio, mas produzi-la sem vivenciá-la é mais difícil. Entretanto, autores tanto do Brasil como dos Estados Unidos - na verdade, de toda a América - produziram obras que se apropriam de aspectos presentes na narrativa fantástica sem necessariamente adentrar o gênero propriamente dito.

\section{O sobrenatural como elemento narrativo}

O principal desses aspectos é o elemento sobrenatural, o qual já foi chamado, por questões epistemológicas, de numinoso (progressivamente desvinculado de crenças e religiões já estabelecidas) e de metaempírico (puramente estético, possível somente nas narrativas de ficção, termo empregado por Furtado 1980: 20). Como já discutido, o elemento sobrenatural pode tanto ser um equívoco de interpretação de um evento natural ou simplesmente um fenômeno desconhecido, mas perfeitamente verificável ou reproduzível na realidade referencial a partir do conhecimento proporcionado pelas ciências naturais. Ou pode ser, conforme Humphrey (1996), um evento fac- 
tualmente sobrenatural, mas tão raro que não pode ser novamente testemunhado nem registrado. Um evento ou ser ou objeto sobrenatural é aquele que supera suas limitações naturais intuitivamente previsíveis, ou seja, realiza feitos para além do que nossos módulos cognitivos esperam das categorias ontológicas que nós, seres humanos, naturalmente inferimos para eles.

A nosso ver, o sobrenatural propriamente dito é apenas a parte visível de um processo de linguagem que tem por função tornar compreensível na escala humana de percepção aquilo que está além da capacidade dos nossos sentidos. É um recurso por meio do qual congregamos diferentes partes de um processo num único elemento, de preferência personificado, para adequá-lo à nossa condição de inferenciadores. Segundo Boyer (2003), nossa capacidade de inferência nos permite reelaborar toda informação que recebemos de forma a torná-la reaproveitável seja para uso futuro, seja para retransmiti-la a um interlocutor. Essa reelaboração funciona de maneira a enquadrar novos conceitos num esquema conceitual já presente em nossa memória e que é recuperado tão logo o mesmo contexto ou um semelhante se manifeste requerendo a presença desse conceito. Um exemplo disso é atribuir agência a seres sobrenaturais quando diante de uma série de eventos positivos ou negativos: alguém dotado de capacidades acima da humana está agindo em meu favor ou contra mim visando algum objetivo.

\section{A personificação de fenômenos de causa desconhecida}

A questão seguinte é: de que forma criamos as explicações que justificam a associação dos eventos sem causa aparente à ação de seres sobrenaturais? Em primeiro lugar, é preciso considerar a natureza da linguagem verbal e, em segundo, o sistema social que a torna possível. Ao considerarmos a estrutura das frases que falamos ou escrevemos, perceberemos que, em geral, temos um esquema segundo o qual alguém realizou ou sofreu uma ação contra ou a favor de outro alguém ou algo. Isso remonta, segundo Dunbar (1997: 148), às origens da linguagem como um instrumento para coletar e distribuir informações acerca dos elementos dos primeiros grupos humanos dotados de fala e que eram grandes o suficiente para um membro isolado agir fora do alcance da visão dos demais membros ou ao menos da maioria deles. Era importante reconhecer aqueles que, de alguma forma, procuravam obter o máximo de vantagens (alimento, água, lugar à sombra, parceiros sexuais) com o mínimo de esforço e assim evitar perder sua parte naquilo que não teria sido obtido sem esforço coletivo (1997: 167). Supomos então que esse contexto teria muito provavelmente moldado não apenas nossa capacidade de "compactar" eventos captados da realidade em frases do tipo sujeito + verbo + objeto/complemento como também estabelecido uma espécie de escala humana de apropriação de eventos: se algo ocorreu, foi obra de alguém visando um objetivo, mas pretendia manter-se oculto ou simplesmente não foi visto.

Além disso, os primeiros grupos humanos tinham de lidar com o fato de também poderem se tornar presas: nossa capacidade de encontrar padrões onde eles muitas vezes não estão, deriva do sistema de detecção de predadores (Atran 2002: 78), a partir do qual é mais vantajoso detectar um predador que não está lá e fugir do que não detectá-lo e ser morto por ele. Mais do que isso, descobrimos que quando o confronto com o predador é inevitável, é possível escapar dele fazendo-lhe uma oferenda ou um sacrifício, criando o conceito de que se algo ou alguém é mais poderoso do que você, é possível encontrar uma saída negociada. 
Dessa forma, diante de um evento de causa desconhecida, nosso sistema de inferências o enquadra da seguinte forma: alguém com capacidades acima das minhas fez isso com alguma intenção. Se me for algo positivo, trata-se de alguém que gosta de mim e me protege. Caso contrário, trata-se de alguém que me detesta e nunca perde uma oportunidade de me prejudicar. $\mathrm{O}$ formato desse "alguém" (basicamente suas características físicas e seus poderes sobrenaturais) será sempre baseado no meio ambiente da cultura em que o grupo do autor estiver inserido: animais, personalidades (antepassados ou grandes líderes), plantas, minerais, fenômenos atmosféricos e astronômicos, acidentes geográficos, tudo isso servirá de matéria prima para a materialização da entidade que, por alguma razão, interfere nas relações de causa e efeito que regem a vida da coletividade à qual pertencem autor e leitor.

Essa reflexão nos permite entender porque existem variadas formas de criaturas sobrenaturais nas mais diversas mitologias, lendas, folclores, contos populares, mas com funções narrativas muito semelhantes. O que João Antonio, escritor brasileiro do século XX, nos proporciona, portanto, não é um conto fantástico em que o sobrenatural se manifesta segundo a problemática do século XIX e que gerou uma tradição entre os autores europeus, pois seu contexto sociocultural é diverso deles. Porém, a capacidade natural do ser humano de criar narrativas que enquadrem o real dentro de relações visíveis de causa e efeito, cujas lacunas são preenchidas criativamente, é a mesma. Seu recurso à figura das fadas para justificar as mazelas sofridas pelo protagonista Jacarandá e o excesso de boa ventura do fazendeiro londrinense Picolo não apenas materializa os agentes sobrenaturais dotados de propósito, que agem por meio de uma força controladora das relações de causa e efeito, interferindo no destino dos personagens, como também subverte a proposta de teóricos do conto maravilhoso, como Propp (2001), ou do fantástico, como Todorov (2010).

Evidentemente isso não exime o autor brasileiro de ter tido contato com narrativas fantásticas ou maravilhosas produzidas por autores estrangeiros, pois, para subverter um gênero narrativo é preciso conhecê-lo. Embora João Antonio não fosse um praticante dessa arte ("Milagre chué" é, na verdade, sua única incursão por essa vereda), apropria-se do elemento sobrenatural não simplesmente como experimento estético, mas para compartilhar sua visão de mundo sobre a situação política e econômica de seu país. Ao "dar uma cara" aos agentes que manipulavam os destinos das diferentes classes sociais brasileiras, João Antonio denuncia indiretamente que a pobreza de uns e a riqueza de outros não são obras do acaso nem falta de ação dessas pessoas: o "milagre econômico" brasileiro dos anos 1970, que acirrou as diferenças entre pobres e ricos, concentrou a riqueza nas mãos de poucos e arremessou milhões de famílias na miséria.

Essa leitura alegórica, embora dominante no que diz respeito a este conto, não escapa da estrutura teleológica brevemente apresentada anteriormente: mesmo podendo ser comodamente considerada uma alegoria do período histórico brasileiro do "Milagre econômico", a presença da fada - encarnada pelas "estrelas", ou seja, entidades responsáveis pelo destino de cada um dos seres humanos na face da Terra - comprova-a independentemente de o conto estar mais próximo do fantástico ou do maravilhoso, do feérico ou da mera alegoria óbvia e acusatória, como apontariam críticos menos cuidadosos.

João Antônio simplesmente subverte a todos esses gêneros sem, no entanto, escapar a este modelo sociocognitivo que ora apresentamos. 


\section{Interpretação e análise: considerações iniciais}

Em fins de 1974, o escritor João Antônio Ferreira Filho (1937-1996) chegou a Londrina, no estado do Paraná, para trabalhar no jornal Panorama (que circularia entre março de 1975 e outubro de 1976), uma iniciativa do empresário Paulo Pimentel.

João Antônio já era um autor respeitado pela crítica desde sua estreia, com o livro de contos Malagueta, Perus e Bacanaço (1963), que lhe rendeu o Prêmio Jabuti de "Melhor livro de contos" e o Prêmio Jabuti de "Revelação de autor" - feito inédito até então -, quando aceitou o convite para trabalhar no referido jornal londrinense. O conto que dá nome a essa coletânea seria publicado, em 1981, na então Tchecoslováquia, sob o título "Paprika, Perus a Hezoun"1, sendo motivo de grande satisfação do autor, que escrevera ao amigo Mylton Severiano, em 27 de agosto de 1979:

Mas o melhor vem agora. A Agentur Dilia fur Theater und Literatur Theatrical and Literary Agency propõe uma tradução de Malagueta, Perus e Bacanaço para a Tcheco-Eslováquia. São de uma cordialidade, de um profissionalismo e de um amadurecimento inusitados aqui no Brasil (Silva 2005:189).

Londrina vivia ainda a prosperidade dos anos de ouro das lavouras de café, iniciados na década de 1950, e era repleta de histórias reais (ou nem tanto) de fortunas erigidas da noite para o dia - e, muitas vezes, perdidas com a mesma rapidez em mesas de jogo ou casas de prostituição -, reforçando a aura de Eldorado que a cidade representava. Esses relatos mirabolantes causaram forte impressão em João Antônio, que dizia:

Londrina, Norte do Paraná, cidade desconcertante, eu desconcertado, 90 por cento são forasteiros, pingentes da vida e o mais bobo acende o cigarro no relâmpago, que a terra não perdoa - sua poeira ou lama fica impregnada, entranhada na roupa, na pele e na alma. Uma terra roxa e barrenta, terra de siena, que se intromete em tudo porque ninguém vem ao Norte do Paraná impunemente (Silva 2005: 104).

Em 10 de março de 1975, o jornal Panorama publicou um conto de João Antônio, intitulado "Jacarandá - a estrela desce", que seria incluído na coletânea Dedo-duro (1982) sob o nome de "Milagre Chué" e também seria a única experiência literária do autor a considerar o elemento sobrenatural.

\section{Jacarandá e o milagre chué: a subversão de Propp e de Todorov}

Como os agentes sobrenaturais do conto "Milagre Chué" são fadas, usaremos como referência o trabalho de Propp para nos referirmos à estrutura básica da narrativa, mas nos reservamos o direito de considerá-lo mais afeito ao fantástico por ocorrer numa realidade que simula aquela em que vivem autor e leitor (com várias ancoragens verificáveis como as cidades brasileiras do Rio de Janeiro e de Londrina e a situação socioeconômica dos brasileiros em geral nos anos 1970). 
Contrariamente ao que defende Torodov (2010), nosso percurso teórico mostra que a confirmação do evento sobrenatural bem como a falta de hesitação do personagem e do leitor diante deste não permite classificá-lo automaticamente como maravilhoso principalmente por causa dos diferentes contextos socioculturais em que surgiram e se consolidaram. Porém, como Propp realiza um trabalho próximo ao sociológico de autores como Bozzetto, Fabre e Bessière, perceber-se-á no decorrer da análise que tal escolha se mostra compatível com nossa proposta. Além disso, muito do que os autores europeus do século XIX produziram, retomou o maravilhoso medieval, seja assimilando-o, seja apenas apropriando-se de algumas de suas características, seja subvertendo-o completamente - o que faz João Antônio um século mais tarde.

Jacarandá, o protagonista do conto "Milagre Chué", é um andarilho sem perspectivas que vive na cidade do Rio de Janeiro, um dos grandes centros urbanos brasileiros. Um narrador onisciente conta a história do pobre-diabo maltrapilho que vive de pequenos expedientes - vendendo óculos escuros "franceses" fabricados no subúrbio de Cascadura, frações de bilhetes de loteria, velas, pentes de osso, periquitos por papagaios a turistas - até ser apanhado pela polícia. Liberado após lavar o chão do Distrito Policial, Jacarandá pega uma carona na boleia de um caminhão e ruma para a cidade de Londrina, onde "dinheiro gordo rodava à grande e solto, fácil, fazendo-se ali fortunas do dia para a noite" (Antônio 2012: 316), em busca de seu Eldorado. O protagonista encontra aí uma grande surpresa e o leitor, também.

Ao chegar a Londrina, Jacarandá é interpelado por Picolo, um homem tão rico quanto insatisfeito com sua riqueza, o qual lhe pede um favor, oferecendo para tanto a quantia de cinquenta cruzeiros: seguir por um cafezal próximo, chamar sua boa fada madrinha e pedir que ela não mais lhe desse riquezas. Ao obedecer e chamar pela "estrela do senhor Picolo", o protagonista vê "na linha do horizonte, um clarão abrindo suave, dourado. Surgiu uma fina carruagem levada por animais brancos, raçudos, limpos e fortes. Magníficos, um desfile. Segurando as rédeas, com doçura, uma fada de condão mágico" (Antônio 2012: 317). E dela ouve que a sina do afilhado é enriquecer ainda mais - e assim será para sempre, pois "não lhe darei um minuto de vida sem pencas de dinheiro. Quanto mais gastar, mais ele ganhará. E não insista” (Antônio 2012: 317). Voltando para dar o recado da bela entidade a Picolo, Jacarandá o faz mais triste e desiludido e, ao se despedir do protagonista, o rico senhor ainda lhe dá mais cinquenta cruzeiros. Entusiasmado com a boa sorte obtida, o protagonista crê estar no Eldorado, afinal, ganhara cem cruzeiros alguns minutos após ter chegado a Londrina - especialmente se considerarmos que o valor do salário mínimo da época era de Cr\$ 532,80 (quinhentos e trinta e dois cruzeiros e oitenta centavos), conforme o decreto $\mathrm{n}^{\circ}$. 75679 de maio de $1975^{2}$.

Contente com os cem cruzeiros ganhos e acreditando ser possível ter a mesma boa estrela de Picolo, Jacarandá indaga a si mesmo "por que ele, madeira de lei e pau para toda obra, não teria também a sua?” (Antônio 2012: 318), resolve partir para o mesmo cafezal e invocar sua própria boa estrela. Ao bradar “estrela de Jacarandá! Apareça!”, presencia uma cena surpreendente:

Ouviu um estrondo medonho na linha do horizonte. O céu pretejou, um relâmpago cortou rápido e triscando, o gajo apavorou-se nas pernas. Veio, rangendo capenga, uma carroça estropiada, puxada por um burro magro, despelado. Segurava, com raiva, as rédeas imundas uma bruxa velha e magra, 
olhos fundos e cara de morte, que lhe berrou, aporrinhada:

- Quem foi o infeliz que me chamou?

(Antônio 2012: 318).

Chamada por seu afilhado, a bruxa faz questão de esbravejar: "Suma daqui, desgraçado! Fique sabendo que você só ganhou aqueles cem cruzeiros porque eu estava dormindo" (Antônio, 2012: 318). Assim prova que somente através de sua inércia um desabonado pode ser contemplado por um pequeno milagre, um milagre "chué" (neologismo que designa algo desprezível, sem qualquer importância).

"Milagre Chué" lança mão da narrativa fantástica para fazer uma paródia irônica de contos maravilhosos, subvertendo os elementos desses contos em que o herói é premiado ao final de uma série de desgostos superados. O referido conto é "o único momento na obra do escritor paulistano em que encontramos a presença do elemento mágico. Esse tipo de manifestação na estética desse autor aparece, justamente, em um contexto de inversão e delineia uma releitura pelo reverso da tradicional fábula infantil” (Ornellas 2008: 235).

Percebe-se que a trajetória de Jacarandá desmente vários ditames regulamentados por Propp (2001) ao discorrer sobre as funções das personagens em sua Morfologia do conto maravilhoso. De acordo com esse autor, a situação inicial do herói é equilibrada e começa a se desalinhar com o "afastamento de um dos membros da família" (Propp 2001: 19). Porém, Jacarandá não tem família nem origem mencionadas e, apurado diante do comissário do distrito policial onde é detido, mente alegando ter "de reforço, uma mãe doente e irmãos que nunca teve" (Antônio 2012: 315). Mais adiante, para conseguir carona em um caminhão, "desfiou uma história milongada numa transportadora de São Cristóvão, em que misturava nova mãe doente com outros irmãos inventados" (Antônio 2012: 316).

Outro aspecto comum ao conto maravilhoso é o fato de que ele "apresenta, em seguida, a chegada repentina (mesmo se, de certo modo preparada) da adversidade. Em vista disso, a situação inicial dá a descrição de um bem-estar particular, por vezes sublinhado propositalmente" (Propp 2001: 20). Contudo, a situação inicial de Jacarandá é sublinhada como drástica já no início da narrativa: "Deu-lhe um ruço. Caiu-lhe um ruço na vida andeja. E estratégia errada. [...] O herói já não se intrujava bem em sua andança pelo Rio" (Antônio 2012: 315). Perseguido desde sempre pelas adversidades, o protagonista de "Milagre Chué" segue ritos e superstições que revelam sua crença no sobrenatural, mas ainda assim "Não havia persignação que lhe regulasse aquele andaço. Nem o raminho de arruda espetado na orelha, nem as três batidas de punho fechado na madeira, nem o seu pelo-sinal três vezes sempre que passava diante de um santo, igreja ou cemitério" (Antônio 2012: 315). E, ironicamente, acaba sendo preso "numa sexta-feira às seis da tarde, vendendo velas ao pé do Convento de Santo Antônio" (Antônio 2012: 315), o que reforça ainda mais a ineficácia de eventuais intervenções do mundo espiritual na vida de Jacarandá.

Também existe no conto maravilhoso um personagem que exerce o papel de provedor do herói, o qual

é encontrado por acaso na mata, no caminho etc. [...]. Tanto o herói-buscador, como o herói-vítima, recebem dele um objeto (geralmente um meio mágico) que lhes permite superar o dano sofrido. Mas antes de receber o meio mágico, o herói é submetido a certas ações bem diferentes entre si, embora todas elas o levem a tomar posse do objeto mágico (Propp 2001: 25). 
Em "Milagre chué", o papel de provedor é exercido pelo rico fazendeiro encontrado, ao acaso, no centro de Londrina - fazendeiro de quem Jacarandá recebe uma prosaica nota de 50 cruzeiros que não irá, ao longo do conto, recompor as humilhações sofridas em suas andanças pregressas nem tampouco ensejar um futuro mais tranquilo ao andarilho. Acrescente-se, ainda, o fato de o herói do conto maravilhoso ser "submetido a uma prova; a um questionário; a um ataque etc.; que o preparam para receber um meio ou um auxiliar mágico" (Propp 2001: 25). No conto examinado, a prova que Picolo exige do herói não o prepara, exatamente, para receber algo mágico mas sim para entrar em contato com uma esperança que desembocará em uma decepção. Além disso, se em narrativas maravilhosas o herói tem, a certa altura, seu dano inicial ou sua carência reparados e "o objeto de sua busca se consegue ou mediante a força ou mediante a astúcia" (Propp 2001: 31), Jacarandá - que não é forte nem é astuto - segue carente e sem perspectivas após seu encontro com sua "boa estrela".

\section{Jacarandá e o milagre chué: a ironia ao "milagre econômico"}

O conto "Milagre chué" mostra a visão cáustica de João Antônio sobre outro milagre: o milagre econômico instaurado pelo governo militar em 1970, na realidade "uma impressionante euforia, que duraria até 1973, com a economia batendo todos os recordes. [...] O 'milagre' se devia à concentração de riqueza nas mãos de $25 \%$ da população, e uma tempestade contínua de dólares provocada pela favorável conjuntura internacional" (Barros 1992: 59). Porém, em 1975, o governo do general Ernesto Geisel já não podia ocultar o fracasso desse plano econômico, pois conforme Barros (1992), a constante alta no custo de vida, o arrocho prolongado dos salários e a crescente concentração de renda tornaram muito difícil a vida das camadas menos favorecidas da população e indisfarçável a sua penúria, visto que

entre 1974 e 1975, segundo dados oficiais do Instituto Brasileiro de Geografia e Estatística (IBGE), $67 \%$ da população (cerca de 72 milhões de pessoas) não consumia o mínimo indispensável de 2.240 calorias diárias para sobreviver e podia ser considerada desnutrida. O próprio discurso governamental admitia a existência de "focos de pobreza absoluta existentes, principalmente na região semiárida do Nordeste e na periferia dos grandes centros urbanos” (Barros 1992: 81).

Ao lidar com o sobrenatural, João Antônio mostra, sob o prisma dos excluídos, sua visão irônica a respeito da situação de quase miséria do brasileiro comum após o fracasso do "milagre econômico" tão propagandeado pelo governo militar. Jacarandá, apesar de se referir a uma árvore grande e forte, é um desses mencionados desnutridos que perambulam pela periferia do Rio de Janeiro à cata de qualquer atividade que lhe sustente a magra sobrevivência. Ele acha mirabolante a narrativa que Picolo faz sobre sua fortuna obtida com café, soja, gado e trigo, mas realmente insólito parece alguém não querer mais ser rico. A ironia da situação ficcional ratifica a postura crítica de João Antônio, que costumava dizer que

fantástica era a realidade das periferias das grandes cidades e não aquilo que uma nomenclatura teórica estabelece, demonstrando um autor que pensou sobremaneira tanto sobre a necessidade 
de uma elaboração vinculada ao real quanto sobre as classificações da crítica literária de sua época. Essa postura pode justificar a sua ironia a um gênero clássico da literatura ocidental (Ornellas 2008: 235).

A ironia joãoantoniana revela-se na surpresa do encontro entre Jacarandá e os seres sobrenaturais determinando o destino tanto de Picolo quanto do protagonista do conto. A fada, consoante Chevalier e Gheerbrant (2007), opera as mais extraordinárias transformações e, num instante, satisfaz ou decepciona os mais ambiciosos desejos. É ela quem cria em Jacarandá a expectativa de encontrar a prosperidade em terra recém-descoberta por ele - terra essa da qual ele sempre ouviu as mais alvissareiras notícias. Personificando a esperança de um pobre homem sem paradeiro e sem perspectiva qualquer, a linda fada que garante a prosperidade de Picolo "representa a capacidade que o homem possui para construir, na imaginação, os projetos que não pôde realizar" (Chevalier e Gheerbrant 2007: 415). É a partir da fala dessa etérea personagem, que sela o afortunado destino de Picolo, que Jacarandá - até então infeliz e frustrado em seus empreendimentos desastrados - cria a ilusão de merecer ser premiado pela boa sorte. Essa breve ilusão acaba destruída pelo encontro com a estrela de Jacarandá, em tudo a antítese da fada-madrinha de Picolo.

É a bruxa feia, enfezada e com cara de morte quem representa a ácida ironia de João Antônio, pois mesmo sendo ela a beleza transfigurada pela miséria da dura e feia realidade socioeconômica do país, permite por falha e omissão que Jacarandá experimente o sabor de uma breve prosperidade.

A linda fada que surge diante do aventureiro Jacarandá pronuncia apenas uma fala que, suficiente para delimitar a sina de seu afilhado Picolo, silencia qualquer tentativa que este porventura arrisque para não mais enriquecer. Nesse sentido também se coloca o discurso da bruxa madrinha de Jacarandá, a qual decreta com uma breve fala o silenciamento de qualquer esperança de enriquecimento que o andarilho possa vir a ter. Ambas as entidades impõem a seus afilhados a vontade delas, independentemente de qualquer atitude ou merecimento deles. Por sua vez, a bruxa do conto "Milagre Chué" atua como o reverso de madrinha ao negar a Jacarandá a prosperidade que ele sonhou encontrar em terras londrinenses; contudo, mesmo contrariando o pedido do protagonista, este obtém a quantia de cem cruzeiros (uma pequena fortuna para seus padrões) a partir da permissão dela, a provedora do início de boa sorte de Jacarandá - mesmo que seja uma boa sorte breve e ilusória, tão chué quanto os milagres que envolvem mais um desafortunado protagonista de João Antônio.

\section{Conclusão}

Como pudemos ver, "Milagre chué” é uma narrativa de ficção que apresenta um elemento sobrenatural, ou seja, personificações de uma série de relações de causa e efeito que resultam numa condição social distinta para cada cidadão por meio de estrelas (fadas, controladoras do destino). Isso ocorre porque todo texto é uma resposta sociocognitiva para uma contingência sociocultural vivenciada pelo autor: no caso de João Antônio, temos a situação socioeconômica do Brasil do início da década de 1970 e a necessidade de enquadrá-la numa escala que possa ser compreendida pelo ser humano. Entretanto, por ser um artista e não um cientista, o escritor brasileiro busca no 
sobrenatural uma forma de "materializar" a razão pela qual Jacarandá está sempre à beira de grandes catástrofes pessoais enquanto Picolo jamais enfrentará um infortúnio sequer.

De certa forma, essa estrutura narrativa se encaixa na lógica do agente com propósito agindo por meio de força controladora, o que torna a narrativa, mesmo apresentando elementos sobrenaturais, inteligível e assimilável pelo leitor, pois, conforme já discutido, tal lógica é inerente à mente humana e é o que todos buscamos quando presenciamos um evento sem causa aparente. No entanto, os gêneros narrativos próximos (fantástico, maravilhoso, feérico, etc.) em questão são subvertidos, mesmo preservando características que os tornam reconhecíveis, tais como a realidade referencial e o evento irreproduzível ou inverificável nessa mesma realidade.

Isso pode significar que, embora a alusão ao milagre econômico seja facilmente verificável neste conto, a estrutura segundo a qual um evento de causa desconhecida possa ter sua origem atribuída a um ser sobrenatural, dotado de propósito, mesmo no século XX, ainda é válida. Além disso, a abordagem sociocognitiva pode permitir entender que as narrativas que recorrem ao sobrenatural têm, de fato, uma origem comum, não histórica e sociológica, mas cognitiva. Tal consideração nos permitiria, portanto, entender que, independentemente de cultura, local ou época, o mecanismo narrativo que atribui agência a eventos de causa desconhecida é intuitivo e inevitável para os seres humanos que tentam prever o futuro (estados alterados de consciência) e ou reaproveitar o passado fornecedor de certezas (coincidências fortuitas).

Por essas razões, o conto "Milagre chué" está, consideradas as condições socioeconômicas e culturais do Brasil do século XX, tão próximo da estrutura teleológica da narrativa fantástica, do conto maravilhoso ou da simples alegoria, bem como do feérico, permitindo, por meio da abordagem sociocognitiva, enxergar que, embora tenhamos atingido um elevado grau de produção artística e tecnológica, nossos cérebros ainda reagem a determinadas narrativas da mesma forma que o fariam há dezenas de milênios: explicando e justificando haver uma realidade invisível povoada por seres que interferem em nossas vidas independentemente da nossa vontade ou atitude.

\section{Referências bibliográficas}

Antônio, J. (2012). Milagre chué. In Contos reunidos. São Paulo: Cosac Naify.

Atran, S (2004). In gods we trust: The evolutionary landscape of religion. New York: Oxford University Press. Barros, E. L. (1992). Os governos militares. 2a edição. São Paulo: Contexto.

Bessière, I. (1974). Le récit fantastique. La poétique de l'incertain. Paris: Larousse.

Boyer, P. (2003). Et l'homme créa les dieux. Paris: Folio.

Bozzetto R. (1988). Le fantastique dans la littérature des États-Unis. In Europe, 707, 3-11.

. (1992). Obscur objet d'un savoir. Fantastique et science-fiction: deux littératures de l'imaginaire.

Aix-en-Provence: Presses Universitaires de Provence.

Bozzetto, R.; Huftier, A. (2004). Les frontières du fantastique. Approches de l'impensable en littérature. Valenciennes: Presses Universitaires de Valenciennes.

Chevalier, J.; Gheerbrant, A. (2007) Dicionário de Símbolos. 21ª edição. Rio de Janeiro: José Olympio.

Dunbar, R. (1996). Grooming, gossip and the evolution of language. Londres: Farber and Farber. 
Fabre, J. (1991). Pour une sociocritique de la littérature fantastique. In A. Faivre (Ed.), La littérature fantastique (pp. 44-55). Paris: Albin Michel.

Faivre, A. (1991). Genèse d’un genre narratif : le fantastique (essai de périodisation). In A. Faivre (Ed.), La littérature fantastique (pp. 15-44). Paris: Albin Michel.

Freud, S. (2010). O inquietante. In Obras completas (vol. 14) (pp. 328-376). Trad. Paulo César de Souza. São Paulo: Companhia das Letras.

Gottschall, J. (2012). The storytelling animal. How stories make us human. Nova York: Houghton Mifflin Harcourt Publishing Company.

Hines, T. (2003). Pseudoscience and the paranormal. New York: Prometheus Books.

Hood, B. (2012) Supersentido. Por que acreditamos no inacreditável. Trad. I. Panazzolo Júnior. Ribeirão Preto: Novo Conceito.

Humphrey, N. (1999). Leaps of faith. Science, miracles and the search for supernatural consolation. Nova York: Copernicus.

Lovecraft, H. P. (2008). Horror sobrenatural em literatura. Trad. C. M. Parciornik. São Paulo: Iluminuras.

Ornellas, C.A. (2008) O conto na obra de João Antônio: uma poética de exclusão. São Paulo: Linear B.

Pierini, F. L. (2017). Uma abordagem sociocognitiva da narrativa fantástica. Revista Abusões, 5, 172-203.

Propp, V. I. (2001). Morfologia do Conto Maravilhoso. Trad. J. Paravich Sarhan. Rio de Janeiro: Forense universitária.

Sade, D. A. F. (2000). Notas sobre romances ou a arte de escrever ao gosto do público. In Os crimes do amor (pp. 27-63). Trad. Magnólia Costa Santos. Porto Alegre: L\&PM.

Silva, M. S. (2005). Paixão de João Antônio. São Paulo: Editora Casa Amarela.

Todorov, T. (2010). Introdução à literatura fantástica. Trad. M. C. Correa Castelo. São Paulo: Perspectiva.

Turner, M. (1997). Literary mind. The origins of thought and language. Nova York: Oxford University Press. 
